\title{
Estimativa de parâmetros genéticos sob duas estratégias de avaliação em híbridos intra e interespecíficos de capim-elefante ${ }^{1}$
}

\section{Liz Carolina da Silva Lagos Cortes Assis², Mario de Andrade Lira ${ }^{3}$, Mércia Virginia Ferreira dos Santos ${ }^{4}$, José Carlos Batista Dubeux Júnior ${ }^{4}$, Márcio Vieira da Cunha ${ }^{3}$}

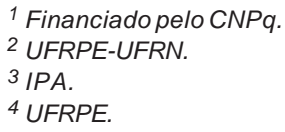

RESUMO - O objetivo neste trabalho foi avaliar os parâmetros genéticos estimados em famílias de híbridos intra e interespecíficos de capim-elefante sob duas formas de avaliação: per se e seleção massal geneticamente estratificada. Foram utilizados dez famílias de híbridos intraespecíficos e dez de híbridos interespecíficos. As características avaliadas foram: altura de planta, desejabilidade agronômica, teor de matéria seca e produção de matéria seca. Foram estimados, para os parâmetros genéticos, a herdabilidade no sentido amplo, variância, coeficiente de variação experimental e genético e correlação genética, fenotípica e ambiental. O experimento foi avaliado em delineamento de blocos casualizados com três repetições. Maior variabilidade genética nas características estudadas foi observada entre os híbridos interespecíficos de capim-elefante e milheto em comparação aos híbridos intraespecíficos de capim-elefante. A herdabilidade teve maiores percentuais para forma per se entre os híbridos estudados. A seleção massal geneticamente estratificada é pouco eficiente na remoção dos efeitos ambientais visando melhorar a precisão experimental.

\footnotetext{
Palavras-chave: correlação, herdabilidade, melhoramento genético, Pennisetum glaucum, Pennisetum purpureum, seleção
}

\section{Estimates of genetic parameters under two evaluation strategies in intra and interespecific hybrids of elephant grass}

\begin{abstract}
The objective of this work was to evaluate the genetic parameters estimated in intra and interespecific hybrid families of elephant grass under two evaluation strategies: per se and genetically stratified mass selection. Ten families of intraespecifc hybrids and ten families of interespecific hybrids were used. The characteristics evaluated were the following: plant height, plant agronomic score, dry matter content and dry matter production. It was estimated, for genetic parameters, heritability in the wide sense, variance, genetic and experimental variation coefficient and genetic, phenotypic and environmental correlation. The experiment was evaluated in a random block design with three repetitions. Greater genetic variability for the studied characteristics were observed among the interespecific hybrids of elephant grass and pearl millet in comparison to the intraespecifc hybrids of elephant grass. Heritability showed higher percentages for per se strategy among the studied hybrids. Genetically stratified mass selection is less effective in removing the environmental effects aiming at improving experimental precision
\end{abstract}

Key Words: correlation, genetic breeding, heritability, Pennisetum glaucum, Pennisetum purpureum, selection

\section{Introdução}

O capim-elefante (Pennisetum purpurem, Schum.), mesmo sendo cultivado por todo o território nacional, necessita de cultivares melhoradas para as diferentes condições edafoclimáticas e sistemas de utilização, e há poucos programas de melhoramento (Pereira et al., 2001).

Em relação aos objetivos desejados em Pennisetum nos programas de melhoramento existentes, a busca de cultivares com propagação por sementes, tolerância a solos de baixa fertilidade, distribuição eqüitativa para produção de matéria seca durante o ano, bem como melhor valor nutritivo e maior produtividade em relação às variedades utilizadas atualmente, é uma constante (Silva, M.C. et al., 2008). A seleção de cultivares com maior teor de matéria seca também vêm sendo estudadas (Silva, M.A. et al., 2008) objetivando melhorar o valor nutritivo da silagem de capim-elefante. 
Baseado nestes objetivos citados, a necessidade de identificar métodos de avaliação que possibilitem diminuir a interferência do ambiente, também vem sendo estudada em outras culturas e pode vir a contribuir para detecção da variabilidade genética de forma mais concreta, acurada e possivelmente de menor custo para a pesquisa. A seleção, por sua vez, é mais efetiva quando age sobre caracteres de alta herdabilidade e que tenham alguma associação com caráter de importância econômica. Daí a relevância de se realizarem trabalhos no sentido de estimar parâmetros genéticos como herdabilidade, correlação e ganhos genéticos, para seleção de cultivares de capimelefante interespecíficos (originados do cruzamento entre o capim-elefante e milheto (Pennisetum glaucum (L.) R. Br.) ou intraespecíficos (oriundo de cruzamento entre capim-elefante) (Daher et al., 2004; Souza Sobrinho et al., 2005).

Devido à necessidade de obter métodos de seleção mais eficientes para potencializar a expressão genética, com menor interferência do ambiente, a partir do comportamento fenotípico, o uso da seleção massal estratificada geneticamente é uma alternativa importante, na aplicação dos parâmetros genéticos. O objetivo da seleção massal é aumentar na população a proporção de genótipos superiores e a seleção massal estratificada geneticamente é mais eficiente porque controla a heterogeneidade ambiental através de estratos e de um genótipo constante.

Neste trabalho objetivou-se avaliar os parâmetros genéticos de famílias de híbridos intra e interespecíficos de capim-elefante sob duas formas de avaliação: per se e massal estratificada geneticamente.

\section{Material e Métodos}

O experimento foi conduzido na Estação Experimental de Itambé, Pernambuco, pertencente ao Instituto Agronômico de Pernambuco - IPA, no período de junho de 2006 a outubro de 2007. O município de Itambé está localizado na microrregião fisiográfica da Mata Seca Pernambucana, com altitude de $190 \mathrm{~m}$, temperatura anual média de $25,1^{\circ} \mathrm{C}$ e pluviosidade anual média de $1.300 \mathrm{~mm}$ (CPRH, 2003). O maior índice de chuvas no período experimental ocorreu entre os meses de março a julho, representando $70 \%$ da média anual. Foi registrado acúmulo de chuvas de 1.049,4 e 1.405,2 mm, respectivamente, em 2006 e 2007 (Figura 1).

Os solos predominantes na Estação Experimental são classificados como Argissolo, com horizonte A proeminente de textura argilosa, fase floresta subcaducifólia e relevo ondulado. Na análise química, o solo da área experimental apresentou os seguintes valores: $\mathrm{pH}\left(\mathrm{H}_{2} \mathrm{O}\right)=5,10$; P disponível $($ Mehlich-I $)=26,67 \mathrm{mg} / \mathrm{dm}^{3} ; \mathrm{Ca}=3,08 \mathrm{cmol}_{\mathrm{c}} / \mathrm{dm}^{3} ; \mathrm{Mg}=$ $1,23 \mathrm{cmol}_{\mathrm{c}} / \mathrm{dm}^{3}, \mathrm{~K}=0,10 \mathrm{cmol}_{\mathrm{c}} / \mathrm{dm}^{3} ; \mathrm{Al}=0,73 \mathrm{cmol}_{\mathrm{c}} / \mathrm{dm}^{3}$ na camada de $0-20 \mathrm{~cm}$ de profundidade.

Em novembro de 2005, foram aplicados 3,0 t/ha de calcário dolomítico e, em fevereiro de 2006, realizada adubação de plantio equivalente a $120 \mathrm{~kg} /$ ha de $\mathrm{K}_{2} \mathrm{O}$ na forma de cloreto de potássio, $30 \mathrm{~kg} / \mathrm{ha}$ de $\mathrm{P}_{2} \mathrm{O}_{5}$, na forma de superfosfato triplo e $40 \mathrm{~kg} / \mathrm{ha}$ de nitrogênio na forma de ureia, com base na análise do solo. No período chuvoso, depois de cada corte, foi aplicada adubação de reposição com nitrogênio (40 kg/ha) na forma de ureia. Não foi realizada irrigação.

As progênies experimentais foram representadas por 263 clones, provenientes de dez famílias de híbridos

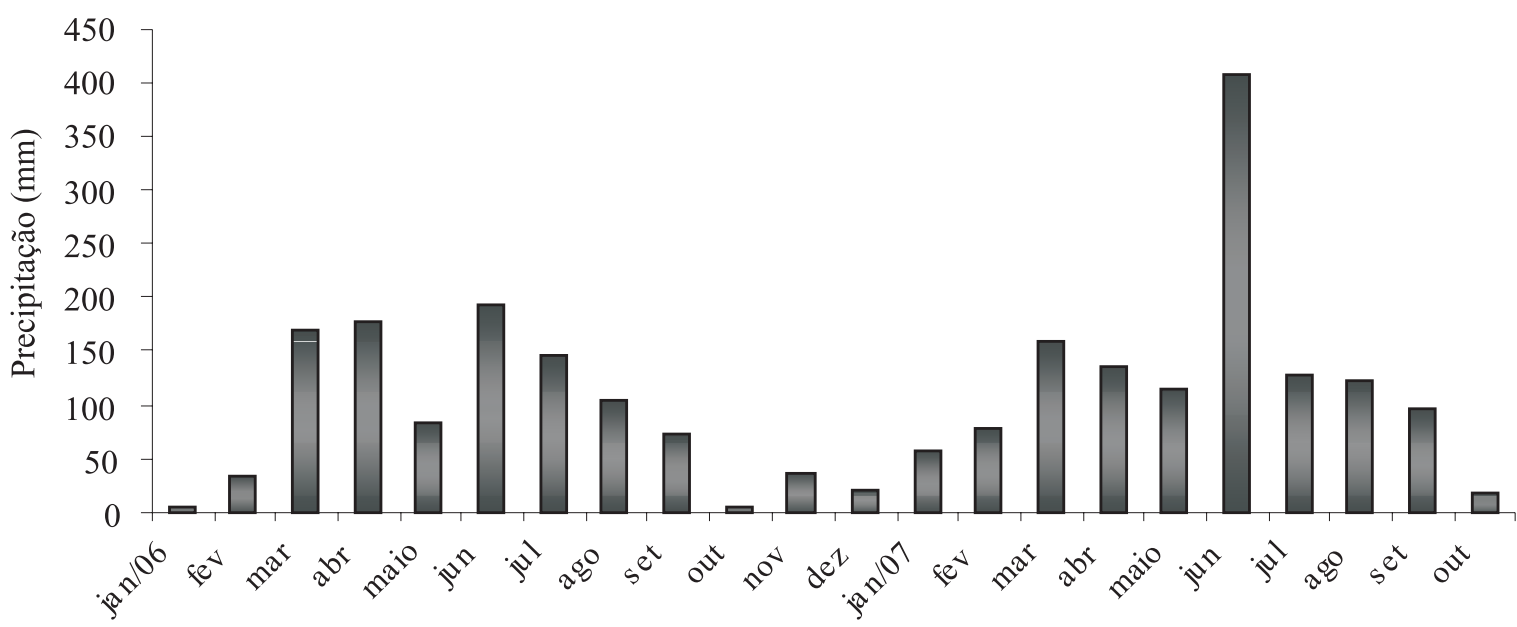

Figura 1 - Precipitação mensal durante o período experimental entre janeiro de 2006 e outubro de 2007. 
intraespecíficos meio-irmãos $\mathrm{F}_{1}$ de capim-elefante e dez famílias de híbridos interespecíficos, oriundos do cruzamento de capim-elefante e o milheto, com diferentes números de progênies/família (Tabela 1). A utilização das famílias experimentais foi obtida a partir da seleção prévia de progênies em bloco de cruzamentos. A seleção prévia dos clones foi realizada na Estação Experimental de Itambé, em área experimental de $2.482 \mathrm{~m}^{2}$, constituída de 506 clones de capim-elefante, entre eles, clones provenientes de cruzamento intra e interespecíficos, optando-se por maior número de clones que sobreviveram em todos os blocos experimentais.

Os híbridos foram avaliados sob duas formas: per se e pelo método de seleção massal estratificada geneticamente, segundo metodologia descrita por Bueno et al. (2001). Na forma per se, as progênies foram avaliadas diretamente, enquanto, na forma geneticamente estratificada, a área experimental foi disposta em estratos, utilizando-se o clone mineirão a cada duas touceiras de progênies avaliadas, sendo os clones ajustados a partir do comportamento desse genótipo comum. O estrato foi constituído de duas progênies e duas plantas do mineirão nas extremidades: a média corrigida foi obtida da média entre os mineirões do estrato, subtraindo-se da média geral do mineirão em cada bloco, em relação aos clones estudados.

Os clones e o mineirão foram representados por uma única planta, com espaçamento de 1,0 × 1,0 m entre touceiras, em delineamento de blocos inteiramente casualizado com três repetições utilizando-se a média de cinco avaliações a uma idade de 70 dias.

As características avaliadas foram altura de planta, desejabilidade agronômica, teor de matéria seca e produção de matéria seca. Na medição da altura da planta, foi utilizada uma fita métrica e considerada a altura do nível do solo até o ponto de curvatura da última folha expandida.

O caráter desejabilidade agronômica foi determinado em cada touceira, por meio de observações visuais, com base no aspecto geral da planta, considerando simultaneamente massa de forragem, intensidade de perfilhamento e susceptibilidade a doenças, utilizando-se escala de notas segundo metodologia descrita por Silva et al. (2009). A escala de notas para desejabilidade foi: 1 . alta desejabilidade agronômica; 2. média desejabilidade agronômica; 3. indesejável e 4. morta. As notas de desejabilidade foram transformadas para $\sqrt{ } \mathrm{x}+1$.

O teor de matéria seca por touceira foi obtido por corte e secagem a $65^{\circ} \mathrm{C}$ de 3 perfilhos/parcela, segundo metodologia de Silva \& Queiroz (2002), e a produção de matéria seca, pelo corte total da touceira e pesagem de toda a massa de forragem, que foi multiplicada pelo teor de matéria seca.

Os parâmetros genéticos estimados foram: variância fenotípica, genotípica e de ambiente; herdabilidade no sentido amplo $\left(\mathrm{h}^{2}\right)$; coeficiente de variação experimental

Tabela 1 - Famílias de híbridos intra e interespecíficos, Itambé-PE

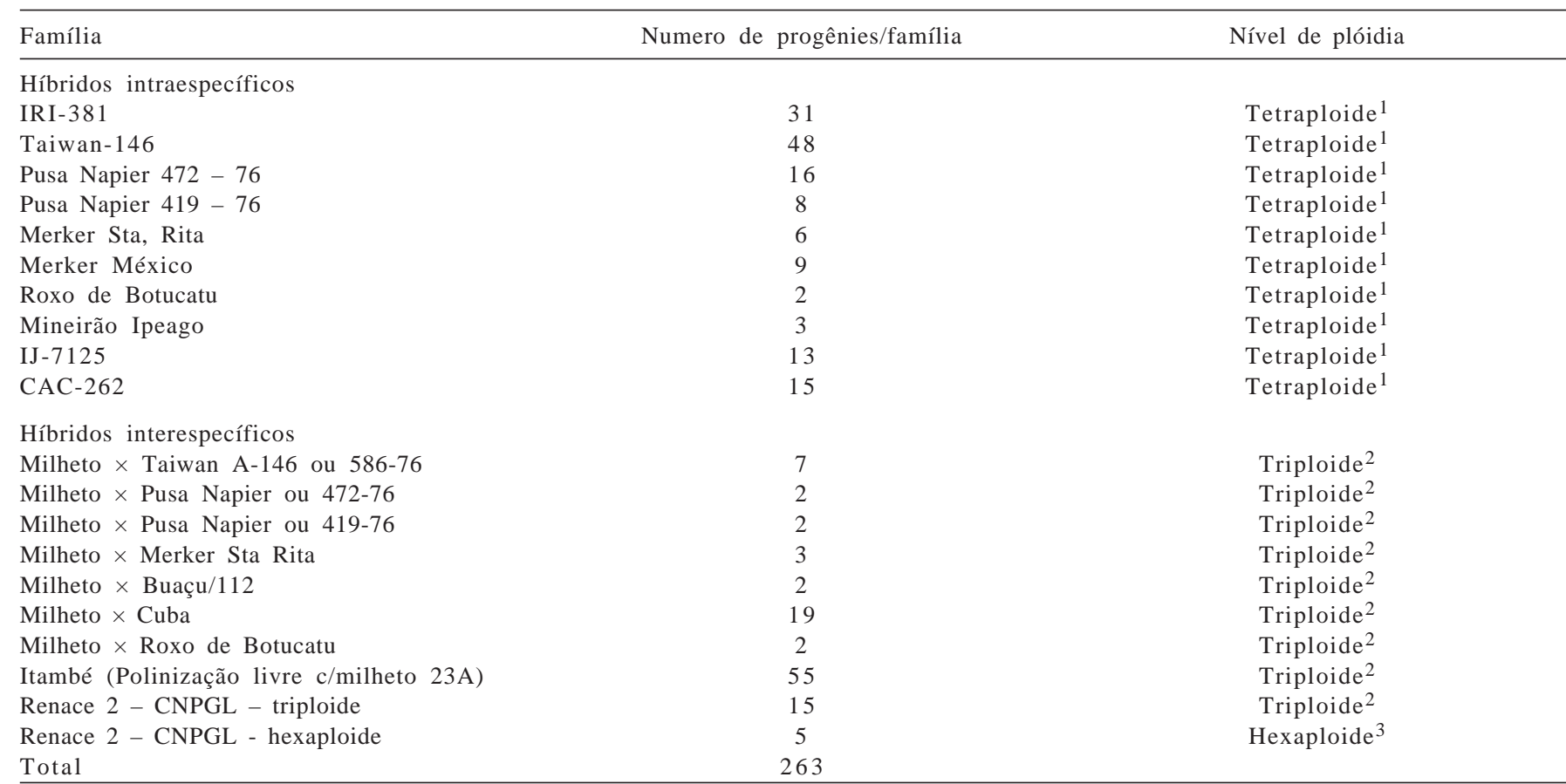

$\mathbf{1}$ Cruzamento entre capim-elefante.

${ }^{2}$ Cruzamento de capim-elefante $\times$ milheto.

${ }^{3}$ Cruzamento de capim-elefante $\times$ milheto com duplicação cromossômica do triploide. 
(CV); coeficiente de variação genética (CVg) e relação $\mathrm{CVg} / \mathrm{CVe}$.

Foram estimados os coeficientes de correlações genética (G), fenotípica (F) e de ambiente (A) entre as médias de famílias, para as características tomada par a par, testadas pelo método Bootstrap, com 5.000 simulações (Cruz, 2006).

As análises de variância, os parâmetros genéticos e as correlações foram estimados segundo metodologia descrita por Cruz et al. (2004). A análise de variância e as médias foram comparadas pelo teste Scott Knott a 5\% de probabilidade. Todas as análises foram realizadas utilizando Programa GENES (Versão 2007.0.0).

\section{Resultado e Discussão}

Para a forma de avaliação per se, foi observado nos híbridos intraespecíficos efeito significativo $(\mathrm{P}<0,05)$ para a altura e o teor de matéria seca e, na forma estratificada geneticamente, apenas para o caráter teor de matéria seca (Tabela 2). Para as dez famílias interespecíficas nas formas de seleção per se e estratificado geneticamente, observou-se efeito significativo $(\mathrm{P}<0,05)$ para todas as características estudadas. Esse resultado evidencia a ampla variabilidade entre os cruzamentos interespecíficos (Tabela 2). Os híbridos interespecíficos proporcionaram maior variabilidade genética em relação aos híbridos intraespecíficos, indicando condições favoráveis à realização do melhoramento, o que torna possível a identificação de famílias superiores e a obtenção de ganho de seleção para estas características, ou seja, observaram-se maiores valores para as características altura, desejabilidade e produção de matéria seca nos híbridos interespecíficos que nos intraespecíficos. O caráter teor de matéria seca apresentou variabilidade similar em relação aos dois tipos de híbridos. Possivelmente, a maior variabilidade evidenciada para os interespecíficos, na maioria das características estudadas, pode ser decorrente da maior diferença genética entre os progenitores de espécie distinta.

Os coeficientes de variação experimental para as características estudadas foram de médio a baixo, seguindo critério sugerido por Ferreira (2000), determinando o caráter produção de matéria seca como o de maior proporção nas duas formas de seleção experimental (Tabela 2), bem como nas duas classes de famílias estudadas.

Mesmo com o aumento do controle local permitido pelo ajuste com o mineirão, não houve ganhos na determinação da variabilidade genética entre as famílias de híbridos intraespecíficos, onde pode ser constato pelos maiores coeficientes de variação observados no

Tabela 2 - Quadrados médios da análise de variância nas formas per se e estratificada em híbridos intra e interespecíficos de capim-elefante

\begin{tabular}{|c|c|c|c|c|}
\hline \multirow[t]{2}{*}{ Fonte de variação } & \multicolumn{4}{|c|}{ Quadrado médio } \\
\hline & Altura $(\mathrm{cm})$ & Desejabilidade (nota) & Teor de MS (\%) & Produção de MSg/touceira \\
\hline & \multicolumn{4}{|c|}{ Per se - intraespecíficos } \\
\hline Blocos & 1342,10 & 0,029 & 11,09 & 26933,39 \\
\hline Famílias & $433,86 *$ & $0,008 \mathrm{~ns}$ & $8,19 * *$ & $30704,70 \mathrm{~ns}$ \\
\hline Resíduo & 49,54 & 0,004 & 0,89 & 11680,11 \\
\hline Média & 156 & 2,1 & 22,35 & 405 \\
\hline \multirow[t]{2}{*}{ CV (\%) } & 4,50 & 4,22 & 4,22 & 26,67 \\
\hline & \multicolumn{4}{|c|}{ Estratificado - intraespecíficos } \\
\hline Blocos & 1563,23 & 0,062 & 11,46 & 38400,79 \\
\hline Famílias & $425,47 n s$ & $0,020 \mathrm{~ns}$ & $6,40 *$ & $29867,68 n s$ \\
\hline Resíduo & 268,94 & 0,018 & 2,23 & 10594,46 \\
\hline Média & 148 & 2,0 & 21,66 & 421 \\
\hline \multirow[t]{2}{*}{ CV (\%) } & 11,07 & 8,17 & 6,89 & 24,44 \\
\hline & \multicolumn{4}{|c|}{ Per se - interespecíficos } \\
\hline Blocos & 3229,30 & 0,0192 & 1,25 & 59031,92 \\
\hline Famílias & $1673,69 * *$ & $0,0349 * *$ & $8,18 * *$ & $252794,03 * *$ \\
\hline Resíduo & 249,58 & 0,0055 & 2,25 & 23508,43 \\
\hline Média & 151 & 2,21 & 23,57 & 431 \\
\hline \multirow[t]{2}{*}{ CV (\%) } & 10,51 & 4,18 & 6,42 & 35,77 \\
\hline & \multicolumn{4}{|c|}{ Estratificado - interespecíficos } \\
\hline Blocos & 4878.73 & 0,0454 & 0,44 & 19850,67 \\
\hline Famílias & $992,12 * *$ & $0,0301 * *$ & $8,96 * *$ & $236231,58 * *$ \\
\hline Resíduo & 197.50 & 0,0053 & 2,48 & 32203,25 \\
\hline Média & 150 & 2,25 & 23,16 & 492 \\
\hline CV (\%) & 9,38 & 4,07 & 6,87 & 37,22 \\
\hline
\end{tabular}

* significância a $5 \%$ de probabilidade; ** significância a $1 \%$ de probabilidade; ns = não-significativo. 
procedimento usual de seleção per se (Tabelas 2 e 3). Segundo Gardner (1961), a utilização da estratificação permite que a seleção se torne mais eficiente, principalmente devido à utilização de uma unidade ambiental independente. Entretanto, o sucesso de um esquema seletivo depende da variação genotípica disponível na população e, sobretudo do seu valor relativo em relação à variação não-genética (Vencovsky, 1987), fato que não ocorreu na maioria das famílias de clones intraespecíficos $\mathrm{F}_{1}$ de meio-irmãos estudadas (Tabela 3).

Granate et al. (2002), trabalhando com famílias de meio-irmãos de milho, afirmaram que a baixa variabilidade genética disponível indica que, possivelmente os ganhos preditos poderão ser relativamente pequenos neste tipo de população. Segundo esses autores, para o aumento desta variabilidade, é necessário um meio estratégico no uso de famílias de irmãos completos ou famílias $\mathrm{S}_{1}$ (autofecundação) que, apesar de serem mais trabalhosas, exploram em maior proporção a variância genética aditiva.

Em relação às famílias de híbridos interespecíficos a seleção massal estratificada geneticamente foi de pouca utilidade, tendo em vista que os coeficientes de variação foram baixos para as características altura, desejabilidade e teor de MS na forma per se. Além disso, para a produção de MS, que apresentou maior coeficiente de variação, demonstrou que a estratificação também não promoveu diminuição da variação ambiental.

A herdabilidade no sentido amplo, das famílias intraespecíficas, para os dados per se foram superiores com 0,89; 0,54; 0,89 e 0,62 em comparação aos estimados na forma estratificada com 0,$37 ; 0,10 ; 0,65$ e 0,61 para as características altura, desejabilidade agronômica, teor de matéria seca e produção de matéria seca, respectivamente (Tabela 3).

A herdabilidade dos caracteres altura, desejabilidade e produção de matéria seca foram sempre superiores nos híbridos interespecíficos. Esse fato, provavelmente, é decorrente da maior variabilidade genética dos interespecíficos (Tabela 3). O teor de matéria seca, por outro lado, foi similar entre os híbridos intra e interespecíficos. A estratificação genética pela correção da variação ambiental promoveu nos híbridos intraespecíficos maior variação ambiental, uma resposta que não era esperada. Nos híbridos

Tabela 3 - Parâmetros genéticos nas formas per se e estratificada em famílias de híbridos intra e interespecíficas de capim-elefante

\begin{tabular}{|c|c|c|c|c|}
\hline Parâmetro & Altura $(\mathrm{cm})$ & Desejabilidade (nota) & Teor de MS (\%) & Produção de MS (g/touceira) \\
\hline & \multicolumn{4}{|c|}{ Per se - intraespecíficos } \\
\hline Herdabilidade & 0,89 & 0,54 & 0,89 & 0,62 \\
\hline Variância fenotípica (média) & 144,62 & 0,0028 & 2,73 & 10234,90 \\
\hline Variância ambiental (média) & 16,51 & 0,0013 & 0,30 & 3893,37 \\
\hline Variância genotípica (média) & 128,10 & 0,0015 & 2,43 & 6341,53 \\
\hline CVg (\%) & 7,24 & 2,28 & 6,98 & 19,66 \\
\hline CVe (\%) & 4,50 & 4,22 & 4,22 & 26,69 \\
\hline \multirow[t]{2}{*}{ Razão CVg/CVe (\%) } & 1,61 & 0,62 & 1,65 & 0,74 \\
\hline & \multicolumn{4}{|c|}{ Estratificado - intraespecíficos } \\
\hline Herdabilidade & 0,37 & 0,10 & 0,65 & 0,61 \\
\hline Variância fenotípica (média) & 141,82 & 0,0067 & 2,13 & 9955,89 \\
\hline Variância ambiental (média) & 89,65 & 0,0061 & 1,74 & 3531,49 \\
\hline Variância genotípica (média) & 52,18 & 0,0006 & 0,39 & 6424,41 \\
\hline CVg (\%) & 4,88 & 1,54 & 5,44 & 19,03 \\
\hline CVe (\%) & 11,07 & 8,17 & 6,88 & 24,44 \\
\hline \multirow[t]{2}{*}{ Razão CVg/CVe (\%) } & 0,44 & 0,19 & 0,79 & 0,78 \\
\hline & \multicolumn{4}{|c|}{ Per se - interespecíficos } \\
\hline Herdabilidade & 0,85 & 0,84 & 0,72 & 0,91 \\
\hline Variância fenotípica (média) & 557,90 & 0,0117 & 2,7263 & 84264,69 \\
\hline Variância ambiental (média) & 83,19 & 0,0019 & 0,7493 & 7836,14 \\
\hline Variância genotípica (média) & 474,70 & 0,0098 & 1,9770 & 76428,53 \\
\hline CVg (\%) & 14,50 & 5,57 & 6,02 & 64,78 \\
\hline Cve $(\%)$ & 10,51 & 4,18 & 6,41 & 35,93 \\
\hline \multirow[t]{2}{*}{ Razão CVg/CVe (\%) } & 1,38 & 1,33 & 0,94 & 1,80 \\
\hline & \multicolumn{4}{|c|}{ Estratificado- interespecíficos } \\
\hline Herdabilidade & 0,80 & 0,82 & 0,72 & 0,86 \\
\hline Variância fenotípica (média) & 330,71 & 0,0100 & 2,9865 & 78743,86 \\
\hline Variância ambiental (média) & 65,83 & 0,0018 & 0,8272 & 10734,42 \\
\hline Variância genotípica (média) & 264,87 & 0,0083 & 2,1593 & 68009,44 \\
\hline CVg (\%) & 10,86 & 5,09 & 6,41 & 54,09 \\
\hline CVe (\%) & 9,38 & 4,07 & 6,87 & 37,22 \\
\hline Razão CVg/CVe (\%) & 1,16 & 1,25 & 0,93 & 1,45 \\
\hline
\end{tabular}

CVe: coeficiente de variação experimental; CVg: coeficiente de variação genético. 
interespecíficos, por outro lado, a estratificação não promoveu mudanças na variabilidade.

Para as famílias de híbridos interespecíficos, a herdabilidade no sentido amplo foi alta para todas as características estudadas (Tabela 3), sob as duas formas de seleção, o que indica pouca interferência do ambiente na variabilidade fenotípica. Maior coeficiente de herdabilidade tende a facilitar a seleção de indivíduos que passarão para os seus descendentes características fenotípicas desejáveis, por métodos simples de melhoramento. A herdabilidade calculada foi a do sentido amplo que inclui toda a variabilidade genética em contraste com a do sentido restrito que leva em conta apenas o componente aditivo. Resende (2002), discutindo sobre o ganho por seleção, informou que a herdabilidade no sentido amplo é adequada quando se realiza propagação vegetativa das plantas selecionadas, enquanto a herdabilidade no sentido restrito é mais adequada na propagação sexuada. Assim, a herdabilidade calculada é adequada na seleção de clones, enquanto a aditiva seria mais adequada na escolha de progenitores.

Entre os componentes da variância, observou-se maior participação da variância genotípica em todas as características estudadas e nas duas formas de avaliação (Tabela 3), indicando que a maior participação da variação fenotípica é respondida pela variação genética (Gomes et al., 2001). As formas de avaliação estudadas obtiveram considerada precisão experimental seguida de alta herdabilidade, uma vez que foram observadas apenas pequenas diferenças entre os CV de cada característica avaliada, baseado nos critérios de classificação descrito por Ferreira (2000).

Além da herdabilidade, o coeficiente de variação genético (CVg) e a relação CVg/CVe também são parâmetros utilizados na quantificação da variabilidade genética disponível na população, quando se deseja determinar o potencial desta para fins de melhoramento (Santos \& Naspolini Filho, 1986). O coeficiente de variação genético, que corresponde ao desvio do padrão genético, expresso em porcentagem da média, é o indicador da grandeza relativa das mudanças em um caráter que podem ser obtidas por meio da seleção, ao longo de um programa de melhoramento. Neste trabalho, os coeficientes oscilaram entre 2,28 e 64,78\%, para a forma per se e 1,54 e 54,09\%, na forma estratificada geneticamente, indicando que há proporcionalidade do ganho em relação à média, no caso de seleção para as respectivas características. A razão CVg/CVe mostrou que existe situação favorável à seleção, na maioria das características e nas duas formas de seleção, com valores maiores ou próximos da unidade em todas as características.

As estimativas de coeficiente de correlação fenotípica, genotípica e ambiental, para os caracteres avaliados em híbridos intraespecíficos (Tabela 4) possibilitaram avaliar a magnitude e o direcionamento das influências de um caráter sobre outro, dando um indicativo de associações entre as características avaliadas. As correlações genéticas mostraram-se superiores às correlações fenotípicas e as de ambiente, nas duas formas de seleção estudadas. Essa

Tabela 4 - Correlação fenotípica, genotípica e ambiental na forma per se e estratificada para as dez famílias intraespecíficas de capim-elefante

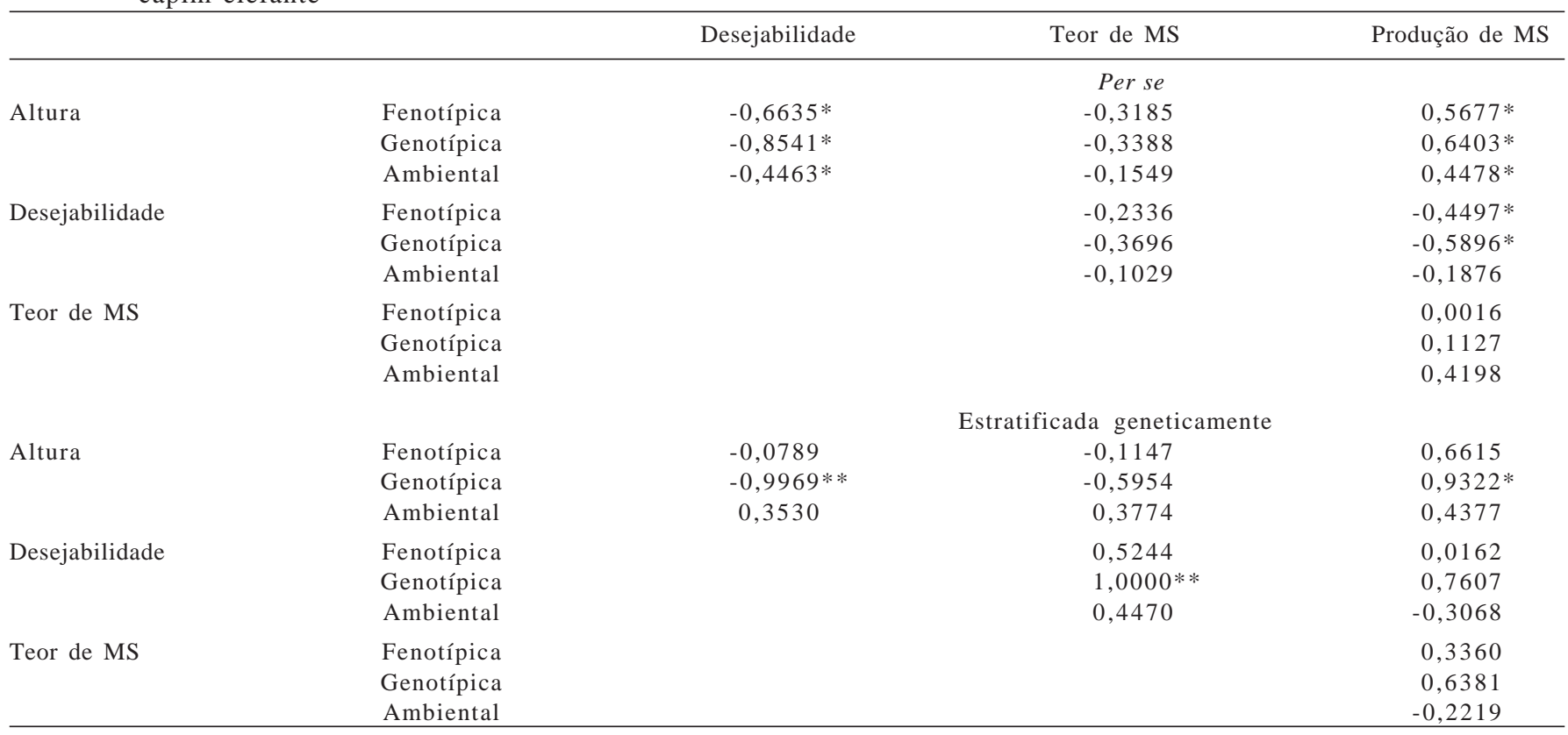

**,* - Significativo a 1 e 5\%, respectivamente, pelo método de bootstrap com 5.000 simulações. 
superioridade seria resultante de efeitos modificadores, de menor proporção do ambiente. Para Kang et al. (1983), diferenças na magnitude das correlações indicam que as correlações genéticas são mais úteis para indicar estratégias de seleção, pois envolvem uma associação de natureza herdável.

Na correlação genética da forma per se, observou-se efeito significativo de $-0,85$ entre altura da planta $\times$ desejabilidade e de 0,64 entre altura da planta × produção de matéria seca. O coeficiente negativo é decorrente das plantas selecionadas, como mais desejáveis, terem menores notas (1), enquanto as indesejáveis foram classificadas com maiores notas (4 para as mortas e 3 para as vivas, mas menos desejáveis). Para a altura da planta, por outro lado, os valores positivos equivalem às plantas mais altas. De acordo com Silva et al. (2009), a característica desejabilidade agronômica é influenciada por fatores como perfilhamento, produção de folhas e susceptibilidade a doenças. No presente trabalho, a produção de matéria seca, por ser uma característica influenciada por diferentes genes, pode vir a se correlacionar diretamente com a desejabilidade, (-0,97 e $-0,93)$ nas duas estratégias de avaliação. Reconhecendo a subjetividade da avaliação da desejabilidade agronômica, a mesma refere-se a um procedimento usual em programas de melhoramento, como o conduzido por Reddy et al. (2007) com a cultura do sorgo granífero, quando o objetivo é selecionar entradas preliminarmente com vistas á avaliação mais detalhada de menor número de famílias.
Com relação ao teor de matéria seca observou-se comportamento negativo de baixa magnitude e não significativo $(\mathrm{P}>0,05)$ entre as correlações para todas as características na forma per se (Tabela 4). Esta baixa correlação indica que as características não são associadas, provavelmente por serem controladas por diferentes bases genéticas (Geraldo et al., 2003).

A correlação genotípica das famílias dos híbridos intraespecíficos, quando calculados com os valores ajustados pelo método geneticamente estratificado, foi significativa e superior a 0,9 entre altura $\times$ desejabilidade, altura $\times$ produção de matéria seca e altura $\times$ teor de matéria seca (Tabela 4). A correlação entre altura $\times$ desejabilidade é negativa face aos menores escores de desejabilidade corresponderem às plantas mais desejáveis, como anteriormente informado para a correlação dos valores per se. A correlação entre desejabilidade e teor de matéria seca foi positiva indicando que as progênies mais desejáveis, que tem menor escore, têm menor teor de matéria seca. Assim, programas de melhoramento de capim-elefante pelo método geneticamente estratificado, ao selecionar as entradas mais desejáveis podem, involuntariamente, estar selecionando progênies de menor teor de matéria seca.

A avaliação em conjunto dos dois métodos de seleção para os híbridos intraespecíficos quando a herdabilidade e correlação genotípica indicam que a seleção das plantas mais altas acarretará a seleção das mais produtivas e de maior desejabilidade. Para selecionar entradas de maior

Tabela 5 - Correlação fenotípica, genotípica e ambiental na forma per se e estratificada geneticamente para as dez famílias de híbridos interespecíficos

\begin{tabular}{|c|c|c|c|c|}
\hline & & Desejabilidade & Teor de MS & Produção de MS \\
\hline Altura & $\begin{array}{l}\text { Fenotípica } \\
\text { Genotípica } \\
\text { Ambiental }\end{array}$ & $\begin{array}{l}-0,7938 * * \\
-0,8116 * \\
-0,6959 * *\end{array}$ & $\begin{array}{l}\text { Per se } \\
-0,0596 \\
-0,1240 \\
-0,0342\end{array}$ & $\begin{array}{l}0,7608 * * \\
0,8632 * * \\
0,0211\end{array}$ \\
\hline Desejabilidade & $\begin{array}{l}\text { Fenotípica } \\
\text { Genotípica } \\
\text { Ambiental }\end{array}$ & & $\begin{array}{l}0,1603 \\
0,2005 \\
0,0175\end{array}$ & $\begin{array}{l}-0,8491 * * \\
-0,9712 * * \\
-0,0018\end{array}$ \\
\hline Teor de MS & $\begin{array}{l}\text { Fenotípica } \\
\text { Genotípica } \\
\text { Ambiental }\end{array}$ & & & $\begin{array}{l}0,0045 \\
0,0519 \\
0,2914\end{array}$ \\
\hline Altura & $\begin{array}{l}\text { Fenotípica } \\
\text { Genotípica } \\
\text { Ambiental }\end{array}$ & $\begin{array}{l}-0,8543 * * \\
-0,9093 * * \\
-0,6169 * *\end{array}$ & $\begin{array}{l}\text { Estratificada geneticamente } \\
\qquad \begin{array}{c}-0,0541 \\
-0,1982 \\
-0,4121\end{array}\end{array}$ & $\begin{array}{l}0,8311 * * \\
0,9797 * * \\
0,0987\end{array}$ \\
\hline Desejabilidade & $\begin{array}{l}\text { Fenotípica } \\
\text { Genotípica } \\
\text { Ambiental }\end{array}$ & & $\begin{array}{l}0,3397 \\
0,4475 \\
0,0262\end{array}$ & $\begin{array}{l}-0,8201 * * \\
-0,9320 * * \\
-0,2175\end{array}$ \\
\hline Teor de MS & $\begin{array}{l}\text { Fenotípica } \\
\text { Genotípica } \\
\text { Ambiental }\end{array}$ & & & $\begin{array}{l}0,0470 \\
0,0149 \\
0,1814\end{array}$ \\
\hline
\end{tabular}

**,* Significativo a 1 e 5\%, respectivamente, pelo método de bootstrap com 5.000 simulações. 
teor de matéria seca, com vistas à seleção para silagem, por exemplo, é necessário avaliar o teor de matéria seca.

Para as 10 famílias de híbridos interespecíficos as correlações fenotípicas, genotípicas e ambientais para as quatro características avaliadas (Tabela 5), observou-se que, na maioria dos casos, os pares de caracteres avaliados apresentaram coeficientes de correlação fenotípica e genotípica com os mesmos sinais e com os coeficientes de correlação genotípicas superiores às fenotípicas, sugerindo que, para a maior parte dos caracteres, a influência ambiental foi baixa e a precisão experimental foi eficiente (Carpentieri-Pípolo \& Bruel, 2002).

As maiores magnitudes para as correlações genéticas estimadas foram entre as características altura $\times$ desejabilidade $(-0,8116 \mathrm{e}-0,9093)$; altura $\times$ produção de MS $(0,8632$ e 0,9797$)$ e desejabilidade $\times$ produção de MS $(-0,9712$ e -0,9320), nas formas per se e estratificado geneticamente, respectivamente. Essas correlações indicam que, similarmente ao afirmado para os clones intraespecíficos, a seleção para produção de forragem pode ser atingida pela seleção das plantas mais altas. A seleção para teor de matéria seca, por outro lado, requer a avaliação desta característica para ser efetiva.

Em experimento realizado por Silva et al. (2009), foram observadas correlações fenotípicas de baixa à média magnitude $(-0,33$ e $-0,52)$ para as correlações altura $\times$ desejabilidade e desejabilidade $\times$ produção de MS, essa baixa correlação provavelmente deve-se a influencia de alguns fatores como perfilhamento, produção de folhas e susceptibilidade a doenças, sobre a desejabilidade em famílias de cruzamento intra e interespescíficas de Pennisetum sp., não permitindo melhor associação entre desejabilidade e aspectos produtivos da planta (altura e produção de MS). Comportamento contrário a Silva et al. (2009) foi encontrado por Oliveira (2007), estudando genótipos de Pennisetum sp., sob pastejo, que observou correlações fenotípicas significativas da desejabilidade com altura e produção de MS de -0,76 e -0,52, respectivamente, corroborando as estimativas encontradas no presente trabalho para as mesmas características.

A correlação genética altura × produção de MS também foi de alta magnitude $(0,86$ e 0,98$)$, para as duas formas de avaliação nos híbridos interespecíficos, comportamento semelhante aos estimados por Silva, M.A. et al. (2008), que observaram alta correlação genética $(0,91)$. Segundo Carpentieri-Pípolo \& Bruel (2002), a altura da planta é um método viável para a estimativa da quantidade de forragem jovem, evidenciando maior proporção de folhas. A baixa magnitude de correlação entre teor de matéria seca com as outras características indica que, a seleção deste caráter, independe da expressividade das outras características estudadas.

A avaliação estratificada geneticamente aumenta muito o número de entradas para avaliação e só deve ser recomendada quando propiciar diminuição significativa na variabilidade ambiental. Neste trabalho a variabilidade ambiental aumentou na avaliação geneticamente estratificada nos híbridos intraespecíficos e não foi afetada nos interespecíficos, consequentemente, a seleção per se foi mais eficiente. A avaliação dos parâmetros genéticos dos híbridos indica que a seleção de plantas mais altas leva indiretamente à seleção de plantas mais produtivas e desejáveis. Para o teor de matéria seca, por outro lado, a seleção tem que ser dirigida diretamente a este caráter.

\section{Conclusões}

A seleção per se foi mais eficiente que a seleção geneticamente estratificada. A seleção para produção de forragem pode ser realizada indiretamente pela seleção da altura da planta. A seleção para teor de matéria seca requer a avaliação direta dessa característica.

\section{Agradecimentos}

À Universidade Federal Rural de Pernambuco (UFRPE) e ao Instituto Agronômico de Pernambuco (IPA). Ao Conselho Nacional de Desenvolvimento Científico e Tecnológico (CNPq).

\section{Referências}

BUENO, L.C.S.; MENDES, A.N.G.; CARVALHO, S.P. Melhoramento genético de plantas: princípios $\mathrm{e}$ procedimentos. Lavras: UFLA, 2001. 282p.

CARPENTIERI-PIPOLO, V.; BRUEL, D.C. Correlações fenotípicas, ganotípicas e ambientais em aceroleira. Revista Brasileira de Fruticultura, v.24, n.1, p.115-119, 2002.

COMPANHIA PERNAMBUCANA DO MEIO AMBIENTE - CPMA. Diagnóstico sócio ambiental do litoral norte de Pernambuco. Recife, 2003. 214p.

CRUZ, C.D.; REGAZZI, A.J.; PATO, A.D. et al. Modelos biométricos aplicados ao melhoramento genético. 3.ed. Viçosa, MG: UFV, 2004. 399p.

CRUZ, C.D. Programa Genes: Análise multivariada e simulação. Viçosa, MG: Editora UFV, 2006. 175p.

DAHER, R.F.; PEREIRA, A.V.; PEREIRA, M.G. et al. Análise de trilha de caracteres forrageiros do capim-efefante (Pennisetum purpureum Schum.). Ciência Rural, v.34, n.5, 2004.

FERREIRA, P.V. Estatística experimental aplicada à agronomia. 3.ed. Maceió: Editora da Universidade Federal de Alagoas EDUFAL, 2000. v.1. 420p.

GARDNER, C.O. An evaluation of effects of mass selection and seed irradiation with thermal neutrons on yield of corn. Crop Science. p.124-245, 1961. 
GERALDO, J.; PEREIRA, M.B., PIMENTEL, C. Herdabilidade e correlações genéticas do teor e da aquisição de nitrogênio em milheto pérola. Revista Universidade Rural, Série Ciências da Vida, v.22, n.2, p.61-70, 2003.

GOMES, J.E.; PERECIN, D.; MARTINS, A.B.G. et al. Análise de agrupamentos de componentes principais no processo seletivo em genótipos de acerola (Malpighia emarginata D.C.). Revista Brasileira de Fruticultura, v.22, n.1, p.36-39. 2001.

GRANATE, M.J.; CRUZ, C.D.; PACHECO, C.A.P. Predição de ganho genético com diferentes índices de seleção no milhopipoca CMS-43. Pesquisa Agropecuária Brasileira, v.37, p.101-108, 2002.

KANG, M.S.; MILLER, J.D.; TALI, P.Y.P. Genetic and phenotypic path analysis and heritability in sugarcane. Crop Science, v.25, p.643-647, 1983.

OLIVEIRA, T.N. Estimativa de parâmetros genéticos na avaliação de clones de Pennisetum sp. sob pastejo. 2007. 99f. Tese (Doutorado em Zootecnia) - Universidade Federal Rural de Pernambuco, Recife.

PEREIRA, A.V.; VALLE, C.B.; FERREIRA, R.P. et al. Melhoramento de forrageiras tropicais. In: NASS, L.; VALOIS, A.C.C.; MELO, I.S. et al. (Eds.). Recursos genéticos e melhoramento. Rondonópolis: Fundação MT, 2001. p.549-601.

REDDY, B.V.S.; RAMAIAH, B.; KUMAR, A.A. et al. Evaluation of sorghum genotypes for the stay-green trait and grain yield. Journal of Semi-Arid Tropical Agricultural Research, v.3, n.1, 2007.

RESENDE, M.D.V. Genética biométrica e estatística no melhoramento de plantas perenes. Brasília: Embrapa Informações Tecnológica, 2002. 975p.
RESENDE, M.D.V.; SOUZA JR., C.L. Seleção de genótipos de milho (Zea mays, L.) em solos contrastantes. Pesquisa Agropecuária Brasileira, v.32, n.8, p.781-788, 1997.

SANTOS, M.X.; NASPOLINI FILHO, W. Estimativas de parâmetros genéticos em três ciclos de seleção entre e dentro de famílias de meios-irmãos no milho (Zea mays L.) Dentado Composto Nordeste. Revista Brasileira de Genética, v.9, n.2, p.307-319, 1986.

SILVA, M.C.; SANTOS, M.V.F.; LIRA, M.A. et al. Ensaios preliminares sobre autofecundação e cruzamentos no melhoramento do capim-elefante. Revista Brasileira de Zootecnia, v.37, p.401-410, 2008.

SILVA, M.A.; LIRA, M.A.; SANTOS, M.V.F. et al. Análise de trilha em caracteres produtivos de Pennisetum sob corte em Itambé, Pernambuco. Revista Brasileira de Zootecnia, v.37, n.7, p.1185-1191, 2008.

SILVA, S.H.B.; SANTOS, M.V.F.; LIRA, M.A. et al. Uso de descritores morfológicos e herdabilidade de caracteres em clones de capim-elefante de porte-baixo. Revista Brasileira de Zootecnia, v.28, n.8, p.1451-1459, 2009.

SILVA, D.J.; QUEIROZ, A.C. Análises de alimentos (métodos químicos e biológicos). 3.ed. Viçosa, MG: Editora UFV, 2002. $235 p$.

SOUZA SOBRINHO, F.; PEREIRA, A.V.; LEDO, F.J.S. et al. Avaliação agronômica de híbridos interespecíficos entre capimelefante e milheto. Pesquisa Agropecuária Brasileira, v.40, n.9, p.873-880, 2005.

VENCOVSKY, R. Herança quantitativa. In: PATERNIANI, E. (Ed.). Melhoramento e produção de milho no Brasil. Piracicaba: ESALQ, 1987. p.122-201. 